\title{
A Model for Sorting Activities to Be Outsourced in Civil Construction Based on ROR-UTADIS
}

\author{
Rachel Perez Palha, Adiel Teixeira de Almeida, and Luciana Hazin Alencar \\ Management Engineering Department, Universidade Federal de Pernambuco, P.O. Box 7462, 50630-970 Recife, PE, Brazil \\ Correspondence should be addressed to Rachel Perez Palha; rachelpalha@gmail.com
}

Received 10 November 2015; Accepted 3 January 2016

Academic Editor: Ben T. Nohara

Copyright (C) 2016 Rachel Perez Palha et al. This is an open access article distributed under the Creative Commons Attribution License, which permits unrestricted use, distribution, and reproduction in any medium, provided the original work is properly cited.

\begin{abstract}
The subcontractor's selection problem is currently treated as a supply chain problem with a prequalification procedure to balance the main objectives of the client: cost, quality, and time. Unfortunately, most of the selection processes are analysed under the same methodology without considering that variations in project, type of activity, and other attributes should affect the chosen method. To provide a novel form of treating subcontractor's selection, we proposed an additive sorting method to categorize activities to be outsourced in civil construction based on ROR-UTADIS method, which is a modification of the UTADIS method that includes new forms of supplying preference information. It was applied in the construction of a brewery in Brazil. It was perceived that the method is applicable and intuitive for decision makers, even though there are quite a few points to be taken, analysed to avoid misclassification.
\end{abstract}

\section{Introduction}

The choice of contractors and subcontractors is problematic studied by several authors over the years due to the clients' difficulty to achieve the best value for invested money since the construction industry has several construction companies with different credibility, sizes, and quality. Reference [1] made a literature review on contractor selection practice in the United Kingdom and realized that the main criteria evaluated by the clients are time, cost, and quality, which vary in priority relation for each client through a trade-off process. The main problem is that some of these criteria are usually subjective and probabilistic, driving the process to a multicriteria decision analysis (MCDA) approach. Therefore, the client plays the role of the decision maker (DM) and needs to analyse his final objectives to have his criteria weighted and reach the best decision.

To solve the contractor selection problem [2] proposed some prequalification criteria, such as contractors' organization, financial considerations, management resources, past experience, and past performance, which are analysed using Multiattribute Analysis. Later the selection is made based on tenderer evaluation by applying Multiattribute Utility Theory (MAUT) [3] in more specific criteria. These criteria were built hierarchically, and each of them had subcriteria to achieve the analysis. Sönmez et al. [4] also advocated for the prequalification of contractors along with evidential reasoning to solve the multicriteria decision-making (MCDM) problem of selection when there are uncertainty and imprecision in the decision process. Lam et al. [5] also proposed a prequalification of contractors for selection based on Support Vector Machine to classify the companies into two classes based on agreed criteria. If the client decides to apply a prequalification analysis, he still needs to carry out a proper selection, which can be driven in the same way of supplier selection's methodologies. In literature, one can find several methodologies.

There are models in which one can find the combination of TOPSIS with other tools, such as fuzzy decision-making approach, [6] proposed a model to calculate the fuzzy positive solutions and fuzzy negative solutions simultaneously, and [7] proposed a framework for supplier selection that includes linear programming. Also, [8] combines FAHP with FTOPSIS, [9] combined a fuzzy DEMANTEL model to 
evaluate the criteria for cause or effect, and [10] used the tools to propose a group decision model. Finally, [11] evaluated green suppliers by using linguistic preferences, [12] used hierarchical fuzzy TOPSIS, and [13] built a model to select green suppliers in Brazil. There are models that combine Minkowski distance and grey number operations [14] and interval data [15].

Models based on FAHP can also be found, such that a Fuzzy hierarchical TOPSIS model is proposed with parametric considerations to avoid violations of the TOPSIS method [16]. Still on this consideration, [17] proposed a model to incorporate the method considerations of benefits, opportunities, costs, and risks, [18] combines FAHP with MAUT, [19] applies the FAHP to assess contractor selection criteria in the group environment, and [20] extended the method to $D$ numbers. Still on fuzzy sets, it can be found along with goal programming for a single DM [21] and to group decision [22] or with ELECTRE III for group decision [23] or green supplier selection [24].

There are combinations of ELECTRE with fuzzy approach [25] and Atanassov interval-valued intuitionistic fuzzy sets [26]. There is analysis combining multiattribute decisionmaking with intuitionistic fuzzy sets [27]. One can also find in literature models combining MAUT with linear programming (LP) for group decision-making [28], models to aggregate crisp values into interval-valued intuitionistic fuzzy sets for group decision-making [29], or the development of new fuzzy aggregation operators for intuitionistic fuzzy in the supplier selection context [30]. In the context of supplier selection, one can find an approach with fuzzy inhomogeneous multiattribute for group decision-making [31] and the combination of VIKOR method with fuzzy sets for group decision-making and applying linear programming for choosing the best supplier [32]. Reference [33] proposed a group decision-making method based on entropy measure with VIKOR method and [34] proposed a compromise solution method for group decision considering both conflicting qualitative and quantitative criteria. Reference [35] proposed an integration of evaluation of criteria under MAUT, but with the use of the ELECTRE method to avoid the rigid axioms of the prior method.

The propositions found in literature are either to prequalify the subcontractors or to select them, but none of them considered that, during the whole cycle of the project, several selections will occur and they may involve different sums of money, risks, qualities, and necessities. If all selections are analysed through the same procedure, it is likely to adopt a methodology that could be either too strict or too loose. Gonçalo and Alencar [36] presented a model in which they apply PROMSORT to sort the activities and materials to be hired or bought into classes, by analysing its strategic impact on the company's goals. Similar to this last article, we propose to apply a sorting procedure, but our goal is to allow the DM to apply different methodologies to subcontractors' selection that will be more appropriate to each class of assignment, since all activities will be hired at some stage of the project. Thus, we propose a model to categorize the activities based on ROR-UTADIS [37] and allow the DM to apply different subcontractors' selection methodologies.
The sorting procedures can be either case-based or elicited. ROR-UTADIS is one of the case-based methods. These methods can consider an underlying additive function, as is the case of UTADIS [38, 39] and its modifications or decision rules to classify the alternatives, as is the case of Dominance-Based Rough Sets Approach (DBSA) [40]. The original Rough Sets Theory could not consider DM's preference information; it was based on "if...then..." rules, that the DM could build, applying them to actions/objects to obtain preference relations. One could achieve a recommendation through the exploitation of these relations. The original rough sets approach required the binary relations defined on it to have some properties, such as being reflexive, transitive, and symmetric, making it difficult to apply to obtain preference information of a DM, but the DBSA relaxed the properties requiring them to be reflexive and transitive. It was also proved that Sugeno Integral cannot be used in DBSA because it requires the set to be single-graded and the sorting problem using DBSA needs more than one grade on the evaluation scale [40]. The DBSA is not directly used in any of the additive sorting methods, but the lower and upper thresholds approximations used for classification in this method resemble the necessary and possible assignments found in the case-based methods with underlying additive function UTADIS ${ }^{\text {GMS }}$ [41] and ROR-UTADIS [37]. Then, this study uses ROR-UTADIS to make the classification of civil construction (CC) activities in different categories of analysis.

This paper is structured into six sections; in the next section, we introduce the current scenario of additive sorting methods, explaining their developments and drawbacks. In Section 3 we present a brief review of the methodology applied in this paper. Section 4 is devoted to explaining the proposed model and its importance to the civil construction (CC). Section 5 presents the selected context of the application and the information required to run the analysis, as well as the results. In Section 6 we discuss the results presented in the previous section. Finally, in Section 7 we conclude with final remarks.

\section{Additive Sorting Methods}

Sorting is problematic, where the DM needs to assign alternatives to predefined classes, which are defined in an ordinal way; classification, on the other hand, is problematic to assign alternatives to predefined nominal classes, that is, nonordered classes. Then, in this study, we propose an application of a sorting method. The researchers in this area show that these methods are important to solve real-world problems, such as performing medical diagnosis through classification of patients into disease groups, assigning personnel to appropriate occupation groups based on their qualifications, credit risk assessment, failure prediction, and so forth. The development of MCDA techniques started with discriminant analysis and recently is based on operations research and artificial intelligence techniques [42]. Sorting models for group decision-making have been also developed [43]. 
In [42] there is a description of the two aspects that involves sorting methodology: the form of criteria aggregation and the method applied to define preferential information. Regarding aggregation, one can find three types: outranking, as in ELECTRE TRI; the utility function, as in UTADIS ([38, 39]); and the simple discriminant functions, which differ from the MAUT methodology because it cannot be considered a preference model. One can elicit preference information directly or indirectly.

An example of direct elicitation is the methodology proposed by [44]. The method consists of defining classes that are not ordered and their criteria. The classification is dichotomous and built through the application of SMARTS method. The name of the method is Multiple Criteria Classification (MCC), once the classes may consider different criteria for its classification. It provides four types of classification: (a) alternatives do not override each other and are all classified; (b) one or more alternatives override each other and are all classified; (c) alternatives do not override each other, and the classification is incomplete, and (d) alternatives override each other and the classification is incomplete.

Case-based sorting methods are indirect forms of definition of preference information that require the presentation of a set of hypothetical or real cases, and the DM is supposed to assign each of them to one predefined class, with such information possible to calibrate the parameters to reflect the DM's preferences. Examples of case-based sorting methods are UTADIS and its variations, DBSA and casebased distance model. The drawback of this approach is that only a few judgments produce the DM's preference and therefore can be consistent with several sets of parameters. To calculate errors and minimize misclassification most of those methods apply linear programing to calculate holistically the parameters. The authors in [45] state that there are three possible outcomes in the solution of this error identification:

(i) The minimization problem has a unique solution with value larger than zero, showing inconsistencies in the preference information.

(ii) The solution is unique and equal to zero; thus there is only one possible solution.

(iii) There are several solutions equal to zero, showing that there are several profiles compatible with the information provided by the DM.

Chen et al. [46] present a proposal of a case-based distance model to solve sorting problematic. It was designed based on an ABC analysis of stock-keeping units in an enterprise. Instead of analysing it based only on annual dollar usage, other criteria were included. It uses Euclidean distances to do the calculations, once the DM can easily understand it. At the beginning of the process, the DM has to define if the criteria increase in preference or decrease and the variability of each criterion, with the information of each alternative on each criterion, is possible to formulate the problem that will be solved using linear programming.
The UTADIS method is a sorting and interactive method, in which the global utility model or additive utility function and class thresholds are calculated through linear programming. Thus, as a result, all parameters of the DM's preference information are calculated, such as the difference between the marginal utilities of two successive values of subintervals and the threshold to ensure the classification and the errors of misclassification. Furthermore, [47] built software known as PREFDIS (PREFerence DIScrimination). It incorporates the original UTADIS method and its variations: UTADIS I, to incorporate distances of correctly classified alternatives from the utility thresholds; UTADIS II, based on mixed integer programming formulation to minimize misclassifications; and UTADIS III that combines the two other variants. The system allows the DM to model nonmonotone preference and includes a postoptimality phase to verify other optimal and suboptimal solutions. Authors of [48] carried out an extensive experimental investigation on UTADIS to shed light on some critical issues regarding the stability of the sorting model developed through preference disaggregation analysis. To correct these problems, they proposed a heuristic (HEUR2), which was tested using Monte Carlo simulation and subjected to an ANOVA.

Köksalan and Özpeynirci [49] presented a modification on UTADIS to diminish the misclassification problems that occurs even when considerable information is available. This methodology does not try to estimate the parameters of an additive utility function. Instead, they impose some restrictions in the linear programming to show if a selected alternative may be assigned to a class. It assumes an additive utility function and takes into account the restrictions created by the DM's assignments to try to place alternatives into categories.

Cai et al. [50] proposed other modification called PUTADIS. It is a progressive approach to assigning alternatives to ordered categories, considering two types of imprecise information and allowing the DM to provide preference information in an interactive form. The global utility function of the DM is built and updated using a heuristic algorithm and later a mixed integer linear programming model is applied in order to identify inconsistencies on preference information. If there is any inconsistency, it is presented to the $\mathrm{DM}$ in order to review his assignments. When it is consistent, then three mixed integer linear programs provide the fittest category and a range of possible categories.

Greco et al. [41] modified UTADIS into UTADIS ${ }^{\text {GMS }}$ bringing to the original method two kinds of assignment to classes: the necessary and the possible assignment. These assignments are computed through linear programming and are based on reference examples. The necessary assignments are the ones that for sure belong to the assigned class and the possible ones are those that could be assigned to two or more classes. The proposition allows the DM to provide imprecise assignment examples (interval assignments) considering the confidence levels of information; in such a case the method expresses the results as ranges of classes that correspond to different confidence levels. It allows the use of nondecreasing marginal value functions, instead of 
piecewise linear marginal value functions, and when the set of assignments is inconsistent, then the DM is required to analyse more reference alternatives. Reference [51] extended the methods UTA ${ }^{\mathrm{GMS}}$ and UTADIS ${ }^{\mathrm{GMS}}$ to group decision, calling them UTA ${ }^{\mathrm{GMS}}$-GROUP and UTADIS ${ }^{\mathrm{GMS}}$-GROUP, respectively. The concepts of necessary and possible assignments are extended to the DMs and the space investigated is the consensus and disagreement among DMs.

Greco et al. [52] extended UTADIS ${ }^{\text {GMS }}$ introducing the concept of the representative value function in robust ordinal regression with the aim of considering complete sets of instances of a preference model compatible with the information provided by the DM; it means that the representativeness of a selected value function is understood in the sense of robustness preoccupation. This method was also extended to group decision in [53] with the same considerations of the method proposed by [50], but considering the representative value function in robust ordinal regression.

Kadziński and Tervonen [54] presented a new approach for multiple criteria sorting problems considering a set of preference model instances compatible with the disaggregation of preferences. The analysis was made using PREFDIS [47], and the possible and necessary assignments were made using robust ordinal regression (ROR). The analysis was enriched with class acceptability indices adapted from Stochastic Multicriteria Acceptability Analysis (SMAA), to analyse the alternatives that were classified as possible, to decide to which class it should be assigned. The ROR approach is the notion of assignment-based weak preference relations and, analogously to the assignments, new necessary and possible assignment-based relations were established, as well as an estimative of assignment based on pairwise outranking indices. Later on the ROR-UTADIS model presented in [37] introduced an assignment-based pairwise comparison to the disaggregation process in which the information provided by the DM comes in the form of imprecise statements referring to the desired assignments for pairs of alternatives, but without assigning the reference alternatives to any concrete class.

Since the ROR-UTADIS method is a holistic additive method that allows the DM to provide more imprecise information, it was selected for this application. It is important for the method to be additive because the DM treats the problem in a compensatory rationality. This method also allows the DM to provide imprecise information when he is not confident about his preference information. Finally, we believe that the extra preference information will decrease number of preference profiles, requiring fewer iterations to reach a recommendation.

\section{Review on ROR-UTADIS}

Kadziński et al. [37] developed a method called RORUTADIS, which holistically calculates all parameters using disaggregation of preferences. The objective is to calculate value functions that are compatible with the reference alternatives. The information provided is incomplete, indirect, and imprecise, guaranteeing, thus, the interactivity and flexibility of the procedure. The information provided may be in the form of assignment examples, assignment-based pairwise comparisons, or desired class cardinalities. The first two options are related to the reference alternatives, and the last is related to the whole set of alternatives. The following mathematical models were built to reproduce preference of the DMs, which can specify information for all types of preference information or provide only the pieces of information he feels comfortable with.

The notation used is as follows.

(i) $A=\left\{a_{1}, a_{2}, \ldots, a_{i}, \ldots, a_{n}\right\}$ is a finite set of $n$ alternatives.

(ii) $A^{R}=\left\{a^{*}, b^{*}, \ldots\right\}$ is a finite set of reference alternatives, assuming $A^{R} \subseteq A$.

(iii) $G=\left\{g_{1}, g_{2}, \ldots, g_{j}, \ldots, g_{m}\right\}$ is a finite set of $m$ evaluation criteria, $g: A \rightarrow \mathbb{R} \forall j \in J=\{1,2, \ldots, m\}$.

(iv) $X_{j}=\left\{x_{j} \in \mathbb{R}: g_{j}\left(a_{i}\right)=x_{j}, a_{i} \in A\right\}$ is the set of all different evaluations of $g_{j}, j \in J$, and its preferential direction is strictly crescent; thus we assume without loss of generality that greater values on $g_{j}\left(a_{i}\right)$, imply a better performance of alternative $a_{i}$ on criterion $j$.

(v) $x_{j}^{1}, x_{j}^{2}, \ldots, x_{j}^{n_{j}(A)}$ are the ordered values of $X_{j}, x_{j}^{k}<$ $x_{j}^{k+1}, k=1,2, \ldots, n_{j}(A)-1$, where $n_{j}(A)=\left|X_{j}\right|$ and $n_{j}(A) \leq n$.

(vi) $g_{j, *}$ and $g_{j}^{*}$ are the lower and upper bounds for the performance scale $g_{j}$; if they are not designated a value, it can be assumed that they are equal to the worst and best performances of existing alternatives; that is, $g_{j, *}=x_{j}^{1}$ and $g_{j}^{*}=x_{j}^{n_{j}(A)}$.

(vii) Let $C_{1}, C_{2}, \ldots, C_{p}$ be $p$ predefined preferenceordered classes, where $C_{h+1}$ is preferred to $C_{h}$, $h=1,2, \ldots, p-1, h \in H, H=\{1,2, \ldots, p\}$.

The preferences of the DMs are presented using an additive value function:

$$
U(a)=\sum_{j=1}^{m} u_{j}\left(g_{j}(a)\right)=\sum_{j=1}^{m} u_{j}(a) .
$$

The basic sets of constraints are constructed to guarantee the marginal value functions $u_{j}$ and they are monotone, nondecreasing and occur in the interval $[0,1]$. There are two sets of constraints: one for the threshold-based procedure (TH) and another to the example-based procedure (EX). This paper only presents the threshold-based procedure equations, except for the base equations, once this was the selected procedure. Consider 


$$
E_{\mathrm{EX}}^{\mathrm{BASE}} \begin{cases}{[M 1] u_{j}\left(x_{j}^{k}\right)-u_{j}\left(x_{j}^{k-1}\right) \geq 0,} & k=2, \ldots, n_{j}(A), j=1, \ldots, m, \\ {[M 2] u_{j}\left(x_{j}^{1}\right) \geq u_{j}\left(g_{j, *}\right),} & u_{j}\left(x_{j}^{n_{j}(A)}\right) \leq u_{j}\left(g_{j}^{*}\right), \\ {[N 1] u_{j}\left(g_{j, *}\right)=0,} & j=1, \ldots, m, \sum_{j=1}^{m} u_{j}\left(g_{j}^{*}\right)=1 .\end{cases}
$$

Due to the limitations on holistic judgment caused by general monotonic marginal value functions, they should be substituted for piecewise linear functions. Thus for each $u_{j}=1, \ldots, m$, a number of characteristic points $\left(\gamma_{j}\right)$ have to be defined; to divide the intervals $\left[g_{j, *} ; g_{j}^{*}\right]$ into $\gamma_{j}-1$ equals subintervals with the endpoints $g_{j}^{s}=g_{j, *}+\left(g_{j}^{*}-\right.$ $\left.g_{j, *}\right) * s-1 / \gamma_{j}-1, s=1, \ldots, \gamma_{j}$. Modifying [M1] and [M2] to adapt to the piecewise linear equations, the set of constraints is as follows:

$$
E_{\mathrm{EX}}^{\mathrm{BASE}} \begin{cases}{[M 1] u_{j}\left(g_{j}^{s}\right)-u_{j}\left(g_{j}^{s-1}\right) \geq 0,} & s=1, \ldots, \gamma_{j}, j=1, \ldots, m, \\ {[M 2] u_{j}\left(x_{j}^{k}\right)=u_{j}\left(g_{j}^{s-1}\right)+\frac{\left(u_{j}\left(g_{j}^{s}\right)-u_{j}\left(g_{j}^{s-1}\right)\right)\left(x_{j}^{k}-g_{j}^{s-1}\right)}{\left(g_{j}^{s}-g_{j}^{s-1}\right)}} & \forall x_{j}^{k} \in\left[g_{j}^{s-1} ; g_{j}^{s}\right], j=1, \ldots, m, k=2, \ldots, n_{j}(A), \\ {[N 1] u_{j}\left(g_{j, *}\right)=0,} & j=1, \ldots, m, \sum_{j=1}^{m} u_{j}\left(g_{j}^{*}\right)=1 .\end{cases}
$$

The representation of the preference of the DM regarding the threshold-based procedure is through a vector $(U, t)$, where $U$ represents the utility and $t$ the threshold vector $t=\left\{t_{1}, \ldots, t_{p-1}\right\}$ that separates the $p$ ordered classes, defined in such a way that $t_{h-1}$ and $t_{h}$ are the lower and upper threshold of class $C_{h}$. The basic set of constraints under this configuration is

$$
E_{\mathrm{TH}}^{\mathrm{BASE}}\left\{\begin{array}{l}
t_{1} \geq \varepsilon, t_{p-1} \leq 1-\varepsilon, \\
t_{h}-t_{h-1} \geq \varepsilon, \quad h=2, \ldots, p-1, \\
E_{\mathrm{EX}}^{\mathrm{BASE}}
\end{array}\right.
$$

The threshold-based sorting model is defined by $(U, \mathbf{t}) \epsilon$ $(U, \mathbf{t})^{R}$ and $a \rightarrow C_{h}$ if and only if $U(a) \in\left[t_{h-1}, t_{h}[\right.$.

In the assignment examples the reference alternatives ( $a^{*} \in A^{R} \subseteq A$ ) are assigned to a range of classes; hence, the desired assignment is

$$
a^{*} \longrightarrow\left[C_{L^{\mathrm{DM}}\left(a^{*}\right)}, C_{R^{\mathrm{DM}}\left(a^{*}\right)}\right]
$$

where $\left[C_{L^{\mathrm{DM}}\left(a^{*}\right)}, C_{R^{\mathrm{DM}}\left(a^{*}\right)}\right]$ is an interval of contiguous classes; if $L^{\mathrm{DM}}\left(a^{*}\right)=R^{\mathrm{DM}}\left(a^{*}\right)=h$ for some $h \in H$, then the assignment is said to be precise and imprecise otherwise:

$$
\begin{aligned}
& L^{U}(a)=\operatorname{Max}\{\{1\} \\
& \left.\quad \cup\left\{L^{\mathrm{DM}}\left(a^{*}\right): U\left(a^{*}\right) \leq U(a), a^{*} \in A^{R}\right\}\right\},
\end{aligned}
$$

$$
\begin{aligned}
& R^{U}(a)=\operatorname{Min}\{\{p\} \\
& \left.\quad \cup\left\{R^{\mathrm{DM}}\left(a^{*}\right): U\left(a^{*}\right) \geq U(a), a^{*} \in A^{R}\right\}\right\} .
\end{aligned}
$$

To guarantee that the assignment example $a^{*}$, which is assigned by the DM to a class range $\left[C_{L^{\mathrm{DM}}\left(a^{*}\right)}, C_{R^{\mathrm{DM}}\left(a^{*}\right)}\right]$, is neither worse than the lower threshold of class $C_{L^{\mathrm{DM}}\left(a^{*}\right)}$ nor worse than the upper threshold of class $C_{R^{\mathrm{DM}}\left(a^{*}\right)}$, the problem is submitted to constraints (7) as follows:

$$
E_{\mathrm{TH}}^{A E}\left\{\begin{array}{l}
\forall a^{*} \in A^{R} \longrightarrow\left[C_{L^{\mathrm{DM}}\left(a^{*}\right)}, C_{R^{\mathrm{DM}}\left(a^{*}\right)}\right]: \\
{\left[T A E_{1}\right] U\left(a^{*}\right) \geq t_{L^{\mathrm{DM}}\left(a^{*}\right)-1},} \\
{\left[T A E_{1}\right] U\left(a^{*}\right)+\varepsilon \leq t_{R^{\mathrm{DM}}\left(a^{*}\right)} .}
\end{array}\right.
$$

Different from the assignment examples, which consist in holistic judgments calculated through recommendations provided by the DM, the assignment-based pairwise comparison is composed of two reference alternatives, $\left(a^{*}, b^{*}\right) \epsilon$ $A^{R} \times A^{R}$, and pairwise comparison between them with imprecise judgment. It is represented as $a^{*}>\underset{\geq k, \mathrm{DM}}{\rightarrow} b^{*}$, meaning that $a^{*}$ and $b^{*}$ are separated by at least $k$ classes and $a^{*}>\underset{\leq l, \mathrm{DM}}{\rightarrow} b^{*}$ meaning that $a^{*}$ and $b^{*}$ are separated by at most $l$ classes. To guarantee these restrictions, the problem is submitted to the following constraints $E_{\mathrm{TH}}^{P C L}$ and $E_{\mathrm{TH}}^{P C U}$ : 


$$
\begin{aligned}
& E_{\mathrm{TH}}^{P C L}\left\{\begin{array}{l}
\forall a^{*}, b^{*} \in A^{R}: a^{*}>\underset{k, \mathrm{DM}}{\rightarrow} b^{*}: \\
\text { for } h=1, \ldots, p-k: \\
{\left[T P C L_{1}\right] U\left(a^{*}\right) \geq t_{h+k-1}-M v_{h}^{P C L}\left(a^{*}, b^{*}\right),} \\
{\left[T P C L_{2}\right] U\left(b^{*}\right)+\varepsilon \leq t_{h}+M v_{h}^{P C L}\left(a^{*}, b^{*}\right),} \\
{\left[T P C L_{3}\right] \sum_{h=1}^{p-k} v_{h}^{P C L}\left(a^{*}, b^{*}\right)=p-k-1,} \\
{\left[T P C L_{4}\right] v_{h}^{P C L}\left(a^{*}, b^{*}\right) \in\{0,1\}, \quad h=1, \ldots, p-k .}
\end{array}\right.
\end{aligned}
$$

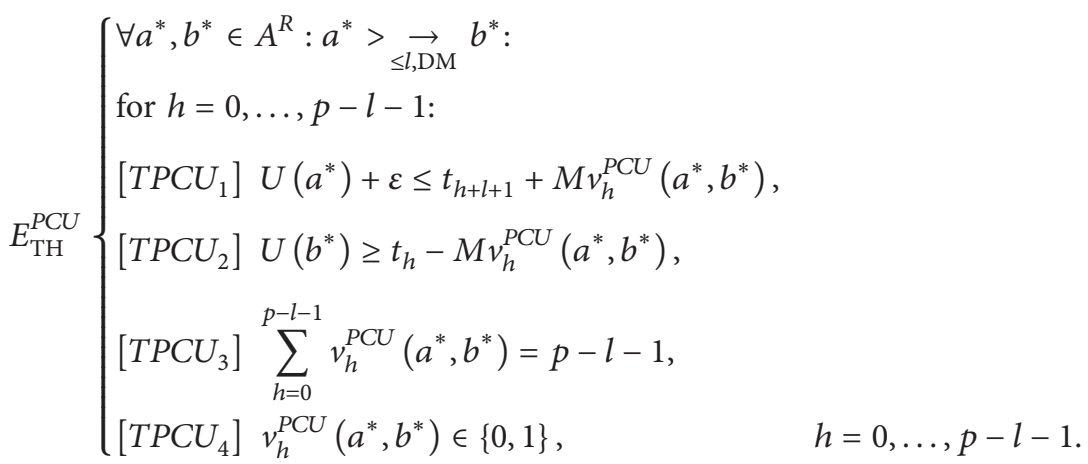

It is also possible for the DM to impose requirements concerning class cardinalities, which is common in realworld sorting problems, such as classification of journals or graduation courses. As a solution, one may include the following constraints, requiring that $C_{h}$ has at least $N_{h, \mathrm{DM}}^{\mathrm{min}}$ and at most $N_{h, \mathrm{DM}}^{\max }$ alternatives, with $N_{h, \mathrm{DM}}^{\min } \leq N_{h, \mathrm{DM}}^{\max }$ :

$$
E^{C C}\left\{\begin{array}{l}
{[C L] \sum_{a \in A} v_{h}(a) \geq N_{h, \mathrm{DM}}^{\min },} \\
{[C U] \sum_{a \in A}^{\max } v_{h}(a) \leq N_{h, \mathrm{DM}}^{\max },} \\
{[C V] \quad v_{h}(a) \in\{0,1\}, \quad a \in A, h \in H .}
\end{array}\right.
$$

The DM can use constraint $[C L]$ or $[C U]$ to model the class cardinality of class $C_{h}$ and the information can be either some alternatives or a frequency. Also, it is necessary also to apply the set of constraints $E_{\mathrm{TH}}^{C C}$ :

$$
E_{\mathrm{TH}}^{\mathrm{CC}} \begin{cases}\forall a \in A, h=1, \ldots, p: & \\ {\left[T C_{1}\right] U(a) \geq t_{h-1}-M\left(1-v_{h}(a)\right),} & \\ {\left[T C_{2}\right] U(a)+\varepsilon \leq t_{h}+M\left(1-v_{h}(a)\right),} & \forall a \in A . \\ {\left[T C_{3}\right] \sum_{h=1}^{p} v_{h}(a)=1,} & \end{cases}
$$

To verify if the set of preference model instances (pairs $\left((U, t)^{R}\right.$ or the value functions $\left.\left.U^{R}\right)\right)$ compatible with the information provided by the DM is not empty, the following problem is considered:

$$
\begin{aligned}
& \text { Maximize: } \varepsilon, \\
& \text { subject to } E^{\text {SORT }},
\end{aligned}
$$

where $E^{\mathrm{SORT}}=E_{\mathrm{TH}}^{\mathrm{BASE}} \cup E_{\mathrm{TH}}^{A E} \cup E_{\mathrm{TH}}^{P C L} \cup E_{\mathrm{TH}}^{P C U} \cup E^{C C} \cup E_{\mathrm{TH}}^{C C}$.

The problem is solved applying mixed integer linear programming and if the solution is not empty, then $E^{\mathrm{SORT}}$ is feasible and $\varepsilon^{*}>0$, where $\varepsilon^{*}$ is the solution of the former equation. If this occurs, it means that the pieces of preference information could be reproduced; if it cannot happen, then the assumed preference model needs to be reviewed. To apply corrections in the model a binary variable should be added in each piece of preference information, especially the ones where the DM could not provide confident information.

Since the model works with a recommendation rather than a solution and the compatible recommendations depend on which piece of preference information is selected, it is important to submit the information to robustness and sensitivity analysis. Thus, the DMs are obliged to confront their value systems, providing insights into the process.

The sets of possible assignments are the ones in which at least one compatible model instance exists that assigns alternative $a$ to class $C_{h}$ and the necessary assignments are the ones where all model instances assign alternative $a$ to class 
$C_{h}$. The possible assignment of $a \in A$ to class $C_{h}, h \in H$, can be verified through the set of constraints $E^{\mathrm{TH}}\left(a \rightarrow{ }^{P} C^{h}\right)$ and the necessary assignment through the set of constraints $E^{\mathrm{TH}}\left(a \rightarrow{ }^{N} C^{h}\right)$ :

$$
\begin{aligned}
& E^{\mathrm{TH}}\left(a \longrightarrow^{P} C^{h}\right)\left\{\begin{array}{l}
{\left[T P_{1}\right] U(a) \geq t_{h-1}, \quad \text { if } h \geq 2,} \\
{\left[T P_{2}\right] U(a)+\varepsilon \leq t_{h}, \quad \text { if } h \leq p-1,} \\
{\left[T P_{3}\right] E^{\mathrm{SORT}}}
\end{array}\right. \\
& E^{\mathrm{TH}}\left(a \longrightarrow^{N} C^{h}\right) \begin{cases}{\left[T N_{1}\right] U(a)+\varepsilon \leq t_{h-1}+M \cdot v_{1},} & \text { if } h \geq 2, \\
{\left[T N_{2}\right] U(a) \geq t_{h}-M \cdot v_{2},} & \text { if } h \leq p-1, \\
{\left[T N_{3}\right]} & v_{1}+v_{2}=1, \\
{\left[T N_{4}\right]} & v_{1}, v_{2} \in\{0,1\}, \\
{\left[T N_{5}\right]} & E^{\mathrm{SORT}} .\end{cases}
\end{aligned}
$$

The sets of possible assignment-based preference relations $a \gtrsim^{\rightarrow, P} b$ are true if $a$ is assigned to a class at least as good as the class of $b$ for at least one compatible model instance, and the necessary assignment-based preference relation $a \gtrsim^{\rightarrow, N} b$ holds if $a$ is assigned to a class at least as good as the class of $b$ for all compatible model instances. These constraints allow direct comparisons between alternatives concerning their sorting recommendations. The relation $a \gtrsim^{\rightarrow, P} b$ is verified through the set of constraints $E_{h}^{\mathrm{TH}}\left(a \gtrsim^{\rightarrow, P} b\right)$ and relation $a \gtrsim^{\rightarrow, N} b$ through the set of constraints $E_{h}^{\mathrm{TH}}\left(a \gtrless^{\rightarrow, N} b\right)$ :

$$
\begin{aligned}
& E_{h}^{\mathrm{TH}}\left(a \gtrsim^{\rightarrow, P} b\right) \begin{cases}{\left[\mathrm{TPAR}_{1}\right] U(a) \geq t_{h-1},} & \text { if } h \geq 2, \\
{\left[\mathrm{TPAR}_{2}\right] U(b)+\varepsilon \leq t_{h},} & \text { if } h \leq p-1, \\
{\left[\mathrm{TPAR}_{3}\right] E^{\mathrm{SORT}}} & \end{cases} \\
& E_{h}^{\mathrm{TH}}\left(a \gtrless^{\rightarrow, N} b\right)\left\{\begin{array}{l}
{\left[T_{\left.N A R_{1}\right]} U(b) \geq t_{h},\right.} \\
{\left[T_{\left.N A R_{2}\right]} U(a)+\varepsilon \leq t_{h},\right.} \\
{\left[T_{\left.N A R_{3}\right]} E^{\mathrm{SORT}} .\right.}
\end{array}\right.
\end{aligned}
$$

To consider $N_{h}^{\min }$ and the $N_{h}^{\max }$ as minimal and maximal cardinality of class $C_{h}$, the mixed integer linear programming problems need to be solved:

$$
\begin{aligned}
\text { Minimize/Maximize: } & \sum_{a \in A} v_{h}(a), \\
\text { subject to } & E^{\text {SORT }},
\end{aligned}
$$

$$
\text { where } v_{h}(a) \in\{0,1\} \text {. }
$$

\section{Sorting Model for Categorizing Activities in Civil Construction}

In the CC context, outsourcing activities is common practice. During the project cycle, several hiring processes are open and closed, and they have different sizes and schedules. They have to be wisely managed to avoid losses and liabilities, and the selection must have a structured methodology, considering that there are a great variety of types of activities, risks, and contract size during this cycle. There will be contracts that will require more attention during its conduction, and others will not, due to their simplicity. The application in this paper consists of a sorting problematic: categorizing all activities with ROR-UTADIS to allow the DM to apply different methods to select subcontractors, improving his administration over the subcontractors.

In this kind of project, it is possible to have more than one DM, but this model does not evaluate the aggregation of DM's preferences. Thus, only one DM in the contractor atmosphere will manage the project, which is the director, and he has total autonomy to make all the decisions in the project he manages. His objectives are aligned with the ones of the company he works for that has a decentralized structure, requiring its president to be completely absent from the projects. Besides being legally and technically responsible for the project, the director has to conquer the project, satisfy the client and manage the relationship between the two companies. Moreover, he is involved in all parts of the process and has to take responsibility for the consequences achieved, so he will be willing to keep the corporate image, reach the best profitability possible in the project, and satisfy and win the client for a long-term relationship.

Other actors will be directly or indirectly involved in the process, such as the analyst, stakeholders, and specialists. There is one actor present in the literature [55], which is not part of this process: the client, as the one that works as an intermediate in the process between the DM and the analyst, 


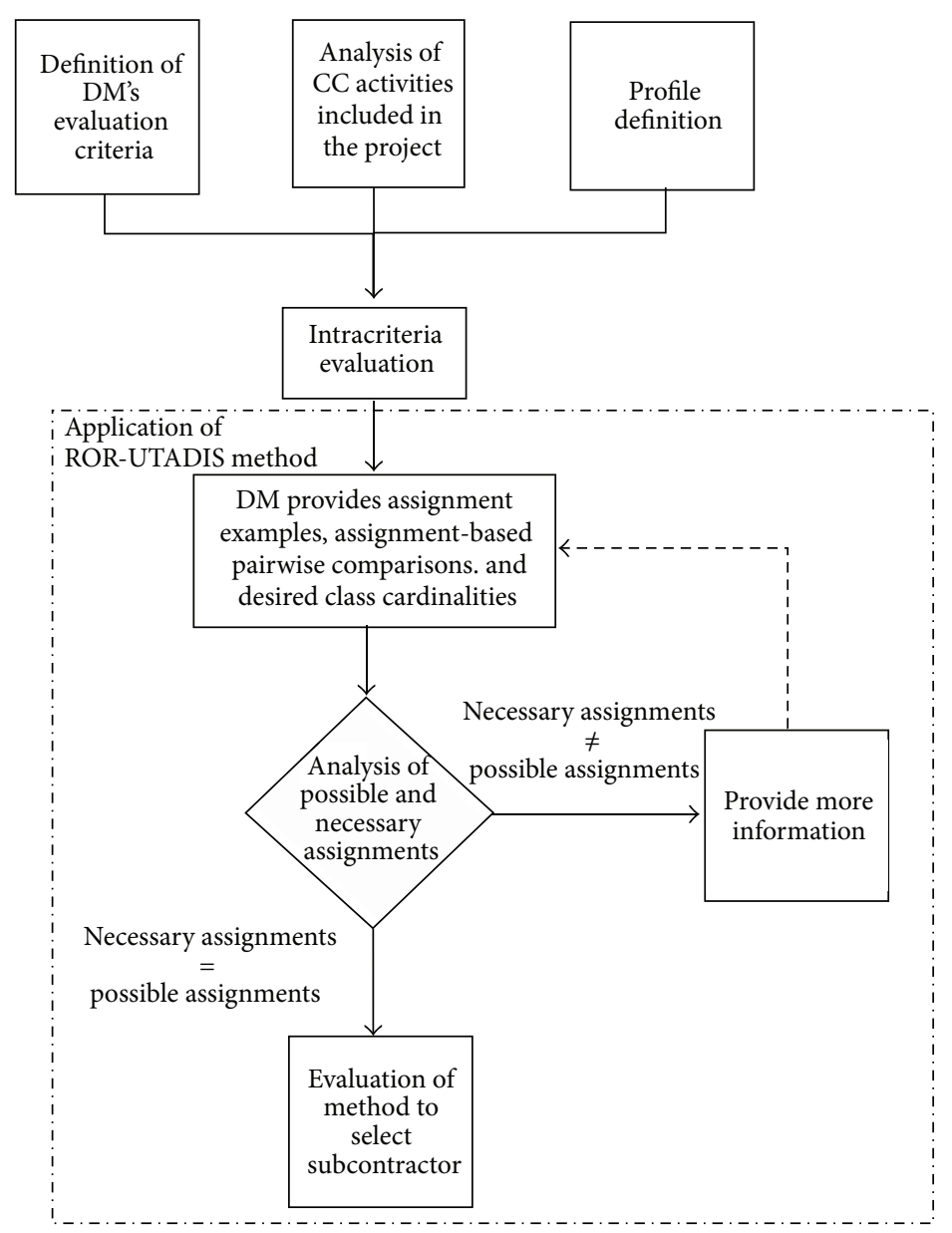

FIGURE 1: Flow of the sorting model for categorizing subcontractors' activities based on ROR-UTADIS.

when the DM is an actor usually absent from the decision process for any reason. However, in this situation the DM will be involved full-time in the decision process, resulting in the exclusion of this actor. The analyst will work on structuring the problems, the bidding procedures, hiring the subcontractors, and managing the relationship between them and the contractor. The stakeholders will be the Ministry of Labour, the Federal Government, the City Hall, the state, the population, environmental agencies, and the client, which can be either public or private. In this problem it is private, therefore present in all steps of the project. There may be specialists hired during the project but will not be involved in the sorting procedure.

Figure 1 shows the flow of the proposed model to categorize subcontractors in civil construction. The analyst has to structure the alternatives, by verifying which civil construction activities will be outsourced. After that he might help the DM to verify his objectives, to relate them to attributes, and evaluate the alternatives. Both actors build the classes' profiles. After this process, the analyst has to create an evaluation matrix of the alternatives and finally, with the help of a Decision Support System (DSS) built in MATLAB, the DM provides his preference information. He will keep providing information until the model converges to one unique solution. In the following section a problem context and its description, as well as the descriptions of the stages of the presented model, are presented.

\section{Sorting Model Application}

The problem context is the CC of a brewery in Pernambuco State, Brazil, in a cost plus contract. Therefore, there is only an estimation of how much it will cost, which is expected to be US\$ 70,000,000.00 (seventy million dollars). Once it is a cost plus contract, several activities have to be outsourced, instead of being carried out by the contractor itself. Thus, many subcontractors might be hired. The objectives of the director, who plays the role of DM, are to preserve the company's image, by avoiding liabilities, problems with population and Ministry of Labour and guaranteeing the safety of the workers related to the project. Those can be achieved by hiring reliable companies, verifying if they are financially healthy and if they work according to the safety laws. The other two objectives are to reach the best profitability that will only be possible enlarging the contract's objective, which can be reached with the third objective of winning the client, attained by delivering quality, low cost and finishing the project in the time agreed between contractor and client. The application 
TABLE 1: Alternatives analysed in the brewery project.

\begin{tabular}{|c|c|}
\hline Alternatives & Description \\
\hline Air conditioning & Activity includes the supply of air conditioning system and installation \\
\hline Concrete & $\begin{array}{l}\text { Concrete supply according to mix informed by the contractor and including installation of the concrete } \\
\text { batching plant inside the project area and availability of concrete mixer truck and concrete pump in the } \\
\text { quantity required }\end{array}$ \\
\hline Containers & Activity includes the supply of containers for the building site and installation (electricity and logic) \\
\hline Heavy equipment & $\begin{array}{l}\text { Activity includes the supply of heavy equipment as planned by the contractor and preventive and } \\
\text { corrective maintenance }\end{array}$ \\
\hline $\begin{array}{l}\text { Molds, shoring, and } \\
\text { scaffolding }\end{array}$ & $\begin{array}{l}\text { The activity includes the supply of molds, shoring, and scaffolding, as well as shoring and scaffolding } \\
\text { projects for the activities and projects presented by the contractor }\end{array}$ \\
\hline Gypsum liner and partition & The activity includes the supply and installation of gypsum liners and partitions \\
\hline $\begin{array}{l}\text { Continuous Flight Auger } \\
\text { Stake (CFA Stake) }\end{array}$ & The activity includes equipment supply, activity, and dynamic and static load reports \\
\hline Hydroseeding & The activity includes material and equipment necessary to the hydroseeding growth \\
\hline Waterproofing & The activity includes material, equipment, and tests to prove the waterproofing \\
\hline Asphalt paving & The activity includes equipment and materials necessary for the asphalt pavement of the designated area \\
\hline Concrete paving & $\begin{array}{l}\text { The activity includes equipment and guarantee for the concrete paving activity; the material is on behalf of } \\
\text { the contractor }\end{array}$ \\
\hline Precast concrete & $\begin{array}{l}\text { The activity includes precast concrete adaptation project, material, equipment, transportation, and } \\
\text { installation of concrete elements }\end{array}$ \\
\hline Food supply & $\begin{array}{l}\text { The activity includes food supply for the personnel designated by the contractor in the building site's } \\
\text { dining hall }\end{array}$ \\
\hline Property security & The activity includes $24 \mathrm{~h}$ of armed property security and patrol \\
\hline Vegetal suppression & The activity includes equipment and licenses to do the vegetal suppression \\
\hline Earthwork & $\begin{array}{l}\text { The activity includes equipment and personnel for the earthwork according to the project provided by the } \\
\text { contractor }\end{array}$ \\
\hline $\begin{array}{l}\text { Transportation of } \\
\text { personnel }\end{array}$ & $\begin{array}{l}\text { The activity includes equipment to transport personnel from and to their residencies in the beginning and } \\
\text { by the end of each business's hours according to the routes provided by the contractor }\end{array}$ \\
\hline
\end{tabular}

was analysed using the threshold-based procedure and, to calculate the results and create an interactive environment, the whole procedure was performed using MATLAB.

5.1. Definition of Alternatives (Activities Included in the Brewery Construction). There were several activities to be outsourced for the construction; some were known to be low risk and low cost activities but required a long-term relation; others were short-term relations but involved high costs or high risks or both. Thus, it was important to list all the alternatives. Table 1 presents all the activities of the project to be hired through a bidding procedure.

5.2. Evaluation of DM's Criteria. The DM expressed his objectives to formulate the sorting procedure based on his preferences; this information was used to define seven criteria to evaluate the alternatives. Table 2 presents these criteria. Three of them are cardinal, and the others are presented in qualitative scale, which are ordered in direction of preference and coded in numbers that were later converted to cardinal scale.

5.3. Profiles. The sorting problematic consists of evaluating several alternatives to sort them into classes; for this purpose it is necessary to analyse which classes are considered. In this problem, the main reason to sort the alternatives into classes is to avoid liabilities by managing carefully the contracts more likely to present those questions. There are three predefined classes to classify the alternatives: high impact (C3), medium impact (C2), and low impact (C1) activities.

The high impact activities are the ones that represent high costs in the project and directly affect the schedule of the project and the client's perception of the activities carried out and their quality. These activities influence the histogram of personnel and guarantee of the project. The contractor has to accompany the subcontractors' personnel due to the long permanence in the building site and interaction with other companies and contractor's labour. It may be a specialized activity and have only a few suppliers or even be a monopoly, so these selection processes have to be carefully accompanied.

The medium impact activities, even though they may consist of a long-term relation, have many available suppliers, and if a delay comes up, it can be recovered by contracting another company to work on the activity simultaneously. It strongly affects the client's satisfaction with the project's accomplishment. There are also some preoccupations with liabilities, once they usually consist of long-term relations. The low impact activities do not have to be hired with the same rigor as the high impact and medium impact contracts, 
TABLE 2: Criteria used to analyse the brewery project.

\begin{tabular}{|c|c|c|c|}
\hline Criteria & Description & Scale & $\operatorname{Min} / \max$ \\
\hline Cost & $\begin{array}{l}\text { Expected cost to accomplish the } \\
\text { activity, calculated before the } \\
\text { bidding procedure }\end{array}$ & Monetary & $\operatorname{Max}$ \\
\hline $\begin{array}{l}\text { Activity } \\
\text { duration }\end{array}$ & $\begin{array}{l}\text { Duration expected on schedule for } \\
\text { the accomplishment of the activity }\end{array}$ & Days & Max \\
\hline $\begin{array}{l}\text { Number of } \\
\text { suppliers }\end{array}$ & $\begin{array}{l}\text { Suppliers' quantity in order to verify } \\
\text { easiness to find companies to carry } \\
\text { out the activity }\end{array}$ & Unit & Min \\
\hline
\end{tabular}

Qualitative (1 to 5)

Qualitative criteria in order to Available evaluate the availability of resources resources in the market (local or surrounding areas)
(1) No available resources near the CC site, all resources must be taken from another city centre

(2) No availability of materials or equipment near the CC site, but the local labour can be trained for qualification purposes

(3) Qualified labour near the CC site, but materials and equipment must be taken from another city centre

(4) Availability of equipment and materials but labour must be trained

(5) All resources are available

Qualitative (1 to 5)

(1) No labour permanence is required and subcontractor is not technically responsible for the activity (equipment renting without activity)

Proxy criteria in order to evaluate Risk through qualitative criteria the risk

exposition exposition analysing technical responsibility and labour permanence in the building site

(2) No labour permanence is required and subcontractor is not technically responsible for the activity, but some visits are necessary (equipment renting without operator but with maintenance)

(3) Labour permanence is required, but subcontractor is not technically responsible for the activity (equipment renting with activity, steel cutting and bending, etc.)

(4) No labour permanence is required, but subcontractor is technically responsible for the activity (projects and project evaluation)

(5) Labour permanence is required, and subcontractor is technically responsible for the activity

Qualitative (1 to 4 )

Necessity of Qualitative criteria in order to maintenance evaluate the necessity of maintenance to attain the activity

(1) Maintenance is not necessary

(2) Only corrective maintenance is necessary

(3) Only preventive maintenance is necessary

(4) Preventive and corrective maintenance are necessary

Qualitative (1 to 5)

(1) Activity does not occur in building site

(2) Activity occurs in the building site but without interaction with other activities or teams

(3) Activity is carried out inside the building site and in contact with other outsourcers' teams and contractor's teams, but without interaction with the activities

Interaction evaluate the interaction with other with other activities to take into account activities security risks and extension of other activities' duration
(4) Activity is carried out inside the building site, without contact with other outsourcers' teams and contractor's teams, but with interaction with the activities

(5) Activity is carried out inside the building site and in contact with other outsourcers' teams and contractor's teams and interacts with the activities since they represent short-time relations with low costs. Usually they do not affect the client's satisfaction. They rarely consist of a source of liability, neither related to problems with labour, nor related with tribute. If there is a contract to make the relation official, the document obligations are relaxed.
5.4. Application of ROR-UTADIS. The sorting model proposed was applied in the data presented in the previous items. As explained in Section 4, we chose to use the ROR-UTADIS method [37], which is a modification of the UTADIS method $[38,39]$. This method was selected due to its compensatory 
TABLE 3: Alternative evaluation matrix.

\begin{tabular}{|c|c|c|c|c|c|c|c|}
\hline \multirow[b]{2}{*}{ Alternatives } & \multicolumn{7}{|c|}{ Criteria } \\
\hline & $\begin{array}{c}\text { Cost (US\$) } \\
\left(g_{1}\right)\end{array}$ & $\begin{array}{c}\text { Activity } \\
\text { duration } \\
(\text { days })\left(g_{2}\right)\end{array}$ & $\begin{array}{c}\text { Number of } \\
\text { suppliers } \\
\left(g_{3}\right)\end{array}$ & $\begin{array}{c}\text { Available } \\
\text { resources } \\
\left(g_{4}\right)\end{array}$ & $\begin{array}{c}\text { Risk } \\
\text { exposition } \\
\left(g_{5}\right)\end{array}$ & $\begin{array}{l}\text { Necessity of } \\
\text { maintenance } \\
\left(g_{6}\right)\end{array}$ & $\begin{array}{c}\text { Interaction } \\
\text { with other } \\
\text { activities }\left(g_{7}\right)\end{array}$ \\
\hline Concrete & $4,000,000.00$ & 360.00 & 5.00 & 3.00 & 5.00 & 4.00 & 5.00 \\
\hline Concrete paving & $700,000.00$ & 60.00 & 4.00 & 1.00 & 5.00 & 4.00 & 5.00 \\
\hline Continuous Flight Auger (CFA) Stake & $700,000.00$ & 180.00 & 12.00 & 1.00 & 5.00 & 4.00 & 4.00 \\
\hline Hydroseeding & $110,000.00$ & 15.00 & 2.00 & 1.00 & 5.00 & 4.00 & 2.00 \\
\hline Earthwork & $1,800,000.00$ & 90.00 & 6.00 & 5.00 & 5.00 & 4.00 & 5.00 \\
\hline Precast concrete & $2,700,000.00$ & 270.00 & 2.00 & 5.00 & 4.00 & 1.00 & 4.00 \\
\hline Transport of personnel & $1,500,000.00$ & 360.00 & 4.00 & 5.00 & 3.00 & 4.00 & 3.00 \\
\hline Molds, shoring, and scaffolding & $150,000.00$ & 360.00 & 4.00 & 4.00 & 5.00 & 1.00 & 5.00 \\
\hline Heavy equipment & $400,000.00$ & 360.00 & 6.00 & 4.00 & 3.00 & 3.00 & 5.00 \\
\hline Food supply & $1,200,000.00$ & 360.00 & 5.00 & 2.00 & 3.00 & 1.00 & 3.00 \\
\hline Gypsum liner & $35,000.00$ & 21.00 & 2.00 & 1.00 & 5.00 & 1.00 & 2.00 \\
\hline Asphalt paving & $90,000.00$ & 4.00 & 2.00 & 5.00 & 5.00 & 4.00 & 2.00 \\
\hline Property security & $500,000.00$ & 360.00 & 4.00 & 5.00 & 3.00 & 1.00 & 3.00 \\
\hline Vegetal suppression & $19,000.00$ & 15.00 & 2.00 & 5.00 & 5.00 & 1.00 & 4.00 \\
\hline Containers & $370,000.00$ & 360.00 & 5.00 & 1.00 & 1.00 & 1.00 & 1.00 \\
\hline Waterproofing & $25,000.00$ & 60.00 & 2.00 & 5.00 & 5.00 & 1.00 & 2.00 \\
\hline Air conditioning & $70,000.00$ & 90.00 & 3.00 & 3.00 & 3.00 & 1.00 & 3.00 \\
\hline
\end{tabular}

TABLE 4: Standardized alternative evaluation matrix.

\begin{tabular}{|c|c|c|c|c|c|c|c|}
\hline \multirow{2}{*}{ Alternatives } & \multicolumn{7}{|c|}{ Criteria } \\
\hline & $g_{1}$ & $g_{2}$ & $g_{3}$ & $g_{4}$ & $g_{5}$ & $g_{6}$ & $g_{7}$ \\
\hline Concrete & 1.0000 & 1.00 & 0.2 & 0.3333 & 1 & 0.8 & 1 \\
\hline Concrete paving & 0.1750 & 0.17 & 0.25 & 1 & 1 & 0.8 & 1 \\
\hline Continuous Flight Auger (CFA) Stake & 0.1750 & 0.50 & 0.08333 & 1 & 1 & 0.8 & 0.8 \\
\hline Hydroseeding & 0.0275 & 0.04 & 0.5 & 1 & 1 & 0.8 & 0.4 \\
\hline Earthwork & 0.4500 & 0.25 & 0.1667 & 0.2 & 1 & 0.8 & 1 \\
\hline Precast concrete & 0.6750 & 0.75 & 0.5 & 0.2 & 0.8 & 0.2 & 0.8 \\
\hline Transport of personnel & 0.3800 & 1.00 & 0.25 & 0.2 & 0.6 & 0.8 & 0.6 \\
\hline Form system, shoring, and scaffolding & 0.0375 & 1.00 & 0.25 & 0.25 & 1 & 0.2 & 1 \\
\hline Heavy equipment & 0.1000 & 1.00 & 0.1667 & 0.25 & 0.6 & 0.6 & 1 \\
\hline Food supply & 0.3000 & 1.00 & 0.2 & 0.5 & 0.6 & 0.2 & 0.6 \\
\hline Gypsum liner & 0.0088 & 0.06 & 0.5 & 1 & 1 & 0.2 & 0.4 \\
\hline Asphalt paving & 0.0225 & 0.01 & 0.5 & 0.2 & 1 & 0.8 & 0.4 \\
\hline Property security & 0.1250 & 1.00 & 0.25 & 0.2 & 0.6 & 0.2 & 0.6 \\
\hline Vegetal suppression & 0.0048 & 0.04 & 0.5 & 0.2 & 1 & 0.2 & 0.8 \\
\hline Containers & 0.0925 & 1.00 & 0.2 & 1 & 0.2 & 0.2 & 0.2 \\
\hline Waterproofing & 0.0063 & 0.17 & 0.5 & 0.2 & 1 & 0.2 & 0.4 \\
\hline Air conditioning & 0.0175 & 0.25 & 0.3333 & 0.3333 & 0.6 & 0.2 & 0.6 \\
\hline
\end{tabular}

nature, allowing criteria to trade-off. As a holistic procedure, there is no need to do a profile characterization, once the restrictions imposed by the preference information supplied by the DM are used to calculate the parameters. The evaluation matrix is presented in Table 3.

In order to apply the first set of restrictions that plays the role of calculating the utility of each alternative, the alternatives must be previously standardized. The marginal value functions were then calculated with the first set of restrictions $\left(E_{\mathrm{TH}}^{\mathrm{BASE}}\right)$ that uses the boundaries and piecewise linear information to do the calculations. Table 4 presents the standardized values but in this table the alternatives are ordered by the value of marginal utility function in a descending order. 
TABLe 5: Assignment examples.

\begin{tabular}{lccr}
\hline Class & First iteration & Second iteration & Third iteration \\
\hline $\mathrm{C} 1$ & Vegetal suppression & & \\
$\mathrm{C} 2$ & Heavy equipment & Transport of personnel, food supply & \\
$\mathrm{C} 3$ & Continuous Flight Auger (CFA) Stake & & Earthwork \\
\hline
\end{tabular}

TABLE 6: Assignment-based pairwise comparisons.

\begin{tabular}{|c|c|c|c|c|c|}
\hline Symbols & First iteration & Symbols & Second iteration & Symbols & Third iteration \\
\hline 11 & Hydroseeding $>\underset{\geq 1, \mathrm{DM}}{\rightarrow}$ gypsum liner & & & 31 & Earthwork $>\underset{\geq 1, \mathrm{DM}}{\rightarrow}$ precast concrete \\
\hline 12 & Containers $>\underset{\geq 0, \mathrm{DM}}{\rightarrow}$ air conditioning & & & & \\
\hline 13 & Concrete $>\underset{\geq 2, \mathrm{DM}}{\rightarrow}$ asphalt paving & & & & \\
\hline 14 & Gypsum liner $>\underset{\leq 1, \mathrm{DM}}{\longrightarrow}$ asphalt paving & & & & \\
\hline
\end{tabular}

TABLE 7: Desired class cardinalities.

\begin{tabular}{lccc}
\hline Class & \multicolumn{2}{c}{ All iterations } & \\
& $N_{h, \mathrm{DM}}^{\min }$ & $N_{h, \mathrm{DM}}^{\max }$ \\
\hline C1 & 3 & 9 \\
$\mathrm{C} 2$ & 3 & 9 \\
$\mathrm{C} 3$ & 3 & 9 \\
\hline
\end{tabular}

The DM provided the system with different types of preference information. In Table 5 it is possible to verify three assignment examples in the first iteration, such as Continuous Flight Auger (CFA) Stake for class 3. Table 6 presents the assignment-based pairwise comparisons; in the first iteration four examples were provided; for example, hydroseeding is considered better than gypsum liner by at least one class. Moreover, in Table 7 it is possible to verify the class cardinalities, which were kept equal in all iterations. The set of compatible instances of the preference model is not empty; therefore, the presented preference statements are consistent. As presented in the third section, once the mixed linear programming converges to a solution, the model can recommend possible and necessary assignments. Table 8 presents the possible assignments for each iteration. In the first iteration four alternatives were assigned to class three that deserves more attention; only one alternative was assigned to the second class, and it was the exemplary assignment, six alternatives were assigned directly to class one, and six alternatives had imprecise assignments, requiring the process to be powered with more information.

In Table 8 the iterations are based on the first recommendation, to diminish the impreciseness of the process. In the second iteration, only two more exemplary alternatives were supplied both to the second class since this was the class with more vagueness on its information. The last iteration was made considering one more exemplary assignment and an assignment-based pairwise comparison. It is important to notice that the assignment-based pairwise comparison is not used to rank alternatives but to create relations among them, to calibrate the model.
Once the DM provided all information, it was possible to reach a final solution, with all alternatives necessarily assigned to one class. Thus, we found a complete preorder, where the alternatives concrete, concrete paving, CFA Stake, hydroseeding, and earthwork were indifferent to each other and strictly preferable to the ones assigned to classes one and two. Alternatives transport of personnel, precast concrete, form system, shoring and scaffolding, heavy equipment, food supply, and gypsum liner were indifferent among them and strictly preferable to alternatives asphalt paving, property security, vegetal suppression, containers, waterproofing, and air conditioning, which created the last set of indifferences.

\section{Discussion of Results}

In the application of this model, the results presented were mostly coherent with the expectations of the DM, except for three alternatives, one in each class. The hydroseeding was assigned to class three due to its performances in criteria available resources, risk exposition, and necessity of maintenance. However, usually the DM would considered class one or two because the cost is too low, and it does not affect the schedule of the project strongly; besides it is a very quick activity that can be carried out at any time of the project. The precast concrete was sorted as class two, due to its performance in the criteria number of suppliers, available resources, and necessity of maintenance. However, as critical activity that influences the whole schedule of the project, the cost and its operations involve many risks the DM, usually, would handle as class three activity, to avoid future liabilities. The last one was property security that was sorted as class one due to the influence of the criteria cost, number of suppliers, available resources, and necessity of maintenance; the DM expected to have it categorized as class three. The model is important to enrich the DM's vision of each activity. The fact that the DM did not agree with the result in some issues shows that the categorization is important to avoid the wrong management in each contract, giving a perspective of aspects he usually would not perceive and spending time in the analysis of an activity that would not bring greater problems. 
TABle 8: Possible assignments.

\begin{tabular}{lccc}
\hline Alternatives & First iteration & Second iteration & Third iteration \\
\hline Concrete & $\mathrm{C} 3$ & $\mathrm{C} 3$ & $\mathrm{C} 3$ \\
Concrete paving & $\mathrm{C} 3$ & $\mathrm{C} 3$ & $\mathrm{C} 3$ \\
CFA Stake & $\mathrm{C} 3$ & $\mathrm{C} 3$ & $\mathrm{C} 3$ \\
Hydroseeding & $\mathrm{C} 3$ & $\mathrm{C} 2-\mathrm{C} 3$ & $\mathrm{C} 3$ \\
Earthwork & $\mathrm{C} 2-\mathrm{C} 3$ & $\mathrm{C} 2-\mathrm{C} 3$ & $\mathrm{C} 2-\mathrm{C} 3$ \\
Transport of personnel & $\mathrm{C} 2-\mathrm{C} 3$ & $\mathrm{C} 2$ & $\mathrm{C} 2$ \\
Precast concrete & $\mathrm{C} 2-\mathrm{C} 3$ & $\mathrm{C} 2$ & $\mathrm{C} 2$ \\
Form system, shoring, and scaffolding & $\mathrm{C} 2-\mathrm{C} 3$ & $\mathrm{C} 2$ & $\mathrm{C} 2$ \\
Heavy equipment & $\mathrm{C} 2$ & $\mathrm{C} 2$ & $\mathrm{C} 2$ \\
Food supply & $\mathrm{C} 1-\mathrm{C} 2$ & $\mathrm{C} 1$ & $\mathrm{C} 2$ \\
Gypsum liner & $\mathrm{C} 1-\mathrm{C} 2$ & $\mathrm{C} 1$ & $\mathrm{C} 2$ \\
Asphalt paving & $\mathrm{C} 1$ & $\mathrm{C} 1$ & $\mathrm{C} 1$ \\
Property security & $\mathrm{C} 1$ & $\mathrm{C} 1$ & $\mathrm{C} 1$ \\
Vegetal suppression & $\mathrm{C} 1$ & $\mathrm{C} 1$ & $\mathrm{C} 1$ \\
Containers & $\mathrm{C} 1$ & $\mathrm{C} 1$ & $\mathrm{C} 1$ \\
Waterproofing & $\mathrm{C} 1$ & $\mathrm{C} 1$ & $\mathrm{C} 1$ \\
Air conditioning & & & \\
\hline
\end{tabular}

The model proposed is applicable and important to verify the output data. Among the holistic models, this one has a very important feature of allowing the DM to provide imprecise information and pairwise comparison through the relative position in the classification whenever he/she feels safe about the information, which greatly improves the generation of preference information. It is easy for the DM to understand the process, even when he is unable to understand the calculations.

However, some issues should be considered in the data analysis. Usually, the sorting process is not compensatory once the categorization of alternatives usually has some acceptability threshold in each criterion that sometimes is called veto and sometimes is called a discordance index. When applying a holistic method, it is not possible to elicit those limits and it is even more impossible to apply them, because the sorting is made considering a class threshold and ignoring criterion thresholds. Also, in the method applied, the marginal utilities are calculated based on the boundaries and piecewise linear information; it is not possible to include in the procedure the elicitation of constant scales the tradeoff among criteria. Thus, some preference information is unavoidably lost during this process. To take into account this consideration it would be necessary to elicit the constant scales before the standardization and include it in the standardization process that could be rather difficult for the DM to understand and apply properly.

The behaviour verified in the first two cases presented could be caused by the lack of preference information on scales constants. That would balance the differences among the criteria and reflect the subtleness of the information provided, once marginal utility values of these alternatives are placed in the threshold limits of the classes they were assigned to. In the last alternative, maybe if the criteria threshold had been elicited, the classification proposed was more similar to the expectations of the DM.

\section{Conclusion}

In this paper, we presented an application of the RORUTADIS method [37] to the context of subcontractor's selection in the construction industry, where, instead of proposing a new methodology to run the selection, we propose to categorize the services prior to the definition of the selection methodology. The model presented results that were coherent with the ones expected, based on previous experience, becoming clear that it can be applied to contexts different than the one presented by the authors. The main motivation to apply this model and not the others is due to its robustness and compatibility with fewer profiles, allowing the information to converge in only a few iterations. This process is easy for the DM to provide information, due to the disaggregation of preference, but have some limitations, since it is harder to elicit scale constants and include them in the analysis.

The inclusion of additional preference information, apart from helping to create stronger restrictions to the problem, even if it allows the DM to consider imprecise assignments, such as assigning one single alternative to more than one class, also gives the DM more confidence in the analysis. Because sometimes he may not be sure about which class to assign a reference alternative but needs to limit the class cardinalities or can compare alternatives, enriching the process with information that usually he would not be able to provide.

Future works may focus on developing an additive method considering direct elicitation of preference information, to include in the analysis constant scale elicitation and 
correct minor misclassification problems that might come up, due to the compensatory nature of the methodology.

\section{Conflict of Interests}

The authors declare that there is no conflict of interests regarding the publication of this paper.

\section{Acknowledgment}

This paper is part of research studies funded by the Brazilian Research Council (CNPq).

\section{References}

[1] G. D. Holt, P. O. Olomolaiye, and F. C. Harris, "A review of contractor selection practice in the U.K. construction industry," Building and Environment, vol. 30, no. 4, pp. 553-561, 1995.

[2] G. D. Holt, P. O. Olomolaye, and F. C. Harris, "Evaluating prequalification criteria in contractor selection," Building and Environment, vol. 29, no. 4, pp. 437-448, 1994.

[3] R. L. Keeney and H. Raiffa, Decisions with Multiple Objectives: Preferences and Value Trade-Offs, Cambridge University Press, Cambridge, UK, 1993.

[4] M. Sönmez, G. D. Holt, J. B. Yang, and G. Graham, "Applying evidential reasoning to prequalifying construction contractors," Journal of Management in Engineering, vol. 18, no. 3, pp. 111-119, 2002.

[5] K.-C. Lam, M. C.-K. Lam, and D. Wang, "Efficacy of using support vector machine in a contractor prequalification decision model," Journal of Computing in Civil Engineering, vol. 24, no. 3, pp. 273-280, 2010.

[6] C.-T. Chen, C.-T. Lin, and S.-F. Huang, "A fuzzy approach for supplier evaluation and selection in supply chain management," International Journal of Production Economics, vol. 102, no. 2, pp. 289-301, 2006.

[7] J. Razmi, M. J. Songhori, and M. H. Khakbaz, "An integrated fuzzy group decision making/fuzzy linear programming (FGDMLP) framework for supplier evaluation and order allocation," International Journal of Advanced Manufacturing Technology, vol. 43, no. 5-6, pp. 590-607, 2009.

[8] Z. Chen and W. Yang, "An MAGDM based on constrained FAHP and FTOPSIS and its application to supplier selection," Mathematical and Computer Modelling, vol. 54, no. 11-12, pp. 2802-2815, 2011.

[9] D. Dalalah, M. Hayajneh, and F. Batieha, "A fuzzy multi-criteria decision making model for supplier selection," Expert Systems with Applications, vol. 38, no. 7, pp. 8384-8391, 2011.

[10] F. E. Boran, S. Genç, M. Kurt, and D. Akay, "A multi-criteria intuitionistic fuzzy group decision making for supplier selection with TOPSIS method," Expert Systems with Applications, vol. 36, no. 8, pp. 11363-11368, 2009.

[11] L. Shen, L. Olfat, K. Govindan, R. Khodaverdi, and A. Diabat, "A fuzzy multi criteria approach for evaluating green supplier's performance in green supply chain with linguistic preferences," Resources, Conservation and Recycling, 2012.

[12] J. Roshandel, S. S. Miri-Nargesi, and L. Hatami-Shirkouhi, "Evaluating and selecting the supplier in detergent production industry using hierarchical fuzzy TOPSIS," Applied Mathematical Modelling, vol. 37, no. 24, pp. 10170-10181, 2013.
[13] D. Kannan, A. B. L. D. S. Jabbour, and C. J. C. Jabbour, "Selecting green suppliers based on GSCM practices: using fuzzy TOPSIS applied to a Brazilian electronics company," European Journal of Operational Research, vol. 233, no. 2, pp. 432-447, 2014.

[14] Y.-H. Lin, P.-C. Lee, T.-P. Chang, and H.-I. Ting, "Multiattribute group decision making model under the condition of uncertain information," Automation in Construction, vol. 17, no. 6, pp. 792-797, 2008.

[15] Z. Yue, "Group decision making with multi-attribute interval data," Information Fusion, vol. 14, no. 4, pp. 551-561, 2013.

[16] J.-W. Wang, C.-H. Cheng, and K.-C. Huang, "Fuzzy hierarchical TOPSIS for supplier selection," Applied Soft Computing Journal, vol. 9, no. 1, pp. 377-386, 2009.

[17] A. H. I. Lee, "A fuzzy supplier selection model with the consideration of benefits, opportunities, costs and risks," Expert Systems with Applications, vol. 36, no. 2, pp. 2879-2893, 2009.

[18] S. Aydin and C. Kahraman, "Multiattribute supplier selection using fuzzy analytic hierarchy process," International Journal of Computational Intelligence Systems, vol. 3, no. 5, pp. 553-565, 2010.

[19] P. Jaskowski, S. Biruk, and R. Bucon, "Assessing contractor selection criteria weights with fuzzy AHP method application in group decision environment," Automation in Construction, vol. 19, no. 2, pp. 120-126, 2010.

[20] X. Deng, Y. Hu, Y. Deng, and S. Mahadevan, "Supplier selection using AHP methodology extended by D numbers," Expert Systems with Applications, vol. 41, no. 1, pp. 156-167, 2014.

[21] Y.-M. Wang and K.-S. Chin, "A linear goal programming priority method for fuzzy analytic hierarchy process and its applications in new product screening," International Journal of Approximate Reasoning, vol. 49, no. 2, pp. 451-465, 2008.

[22] A. K. Kar, "Revisiting the supplier selection problem: an integrated approach for group decision support," Expert Systems with Applications, vol. 41, no. 6, pp. 2762-2771, 2014.

[23] T. Ertay, A. Kahveci, and R. M. Tabanl, "An integrated multicriteria group decision-making approach to efficient supplier selection and clustering using fuzzy preference relations," International Journal of Computer Integrated Manufacturing, vol. 24, no. 12, pp. 1152-1167, 2011.

[24] C.-W. Tsui and U.-P. Wen, "A hybrid multiple criteria group decision-making approach for green supplier selection in the TFT-LCD industry," Mathematical Problems in Engineering, vol. 2014, Article ID 709872, 13 pages, 2014.

[25] T.-Y. Chen, "An ELECTRE-based outranking method for multiple criteria group decision making using interval type-2 fuzzy sets," Information Sciences, vol. 263, pp. 1-21, 2014.

[26] J. Xu and F. Shen, "A new outranking choice method for group decision making under Atanassov's interval-valued intuitionistic fuzzy environment," Knowledge-Based Systems, vol. 70, pp. 177-188, 2014.

[27] S.-P. Wan and D.-F. Li, "Fuzzy LINMAP approach to heterogeneous MADM considering comparisons of alternatives with hesitation degrees," Omega, vol. 41, no. 6, pp. 925-940, 2013.

[28] A. Sanayei, S. F. Mousavi, M. R. Abdi, and A. Mohaghar, "An integrated group decision-making process for supplier selection and order allocation using multi-attribute utility theory and linear programming," Journal of the Franklin Institute, vol. 345, no. 7, pp. 731-747, 2008.

[29] Z. Yue and Y. Jia, "A method to aggregate crisp values into interval-valued intuitionistic fuzzy information for group decision making," Applied Soft Computing, vol. 13, no. 5, pp. 23042317, 2013. 
[30] F. Wang, S. Zeng, and C. Zhang, "A method based on intuitionistic fuzzy dependent aggregation operators for supplier selection," Mathematical Problems in Engineering, vol. 2013, Article ID 481202, 9 pages, 2013.

[31] D.-F. Li and S.-P. Wan, "A fuzzy inhomogenous multiattribute group decision making approach to solve outsourcing provider selection problems," Knowledge-Based Systems, vol. 67, pp. 7189, 2014.

[32] A. Sanayei, S. F. Mousavi, and A. Yazdankhah, "Group decision making process for supplier selection with VIKOR under fuzzy environment," Expert Systems with Applications, vol. 37, no. 1, pp. 24-30, 2010.

[33] A. Shemshadi, H. Shirazi, M. Toreihi, and M. J. Tarokh, "A fuzzy VIKOR method for supplier selection based on entropy measure for objective weighting," Expert Systems with Applications, vol. 38, no. 10, pp. 12160-12167, 2011.

[34] B. Vahdani, S. M. Mousavi, H. Hashemi, M. Mousakhani, and R. Tavakkoli-Moghaddam, "A new compromise solution method for fuzzy group decision-making problems with an application to the contractor selection," Engineering Applications of Artificial Intelligence, vol. 26, no. 2, pp. 779-788, 2013.

[35] A. T. de Almeida, "Multicriteria decision model for outsourcing contracts selection based on utility function and ELECTRE method," Computers \& Operations Research, vol. 34, no. 12, pp. 3569-3574, 2007.

[36] T. E. E. Gonçalo and L. H. Alencar, "A supplier selection model based on classifying its strategic impact for a company's business results," Pesquisa Operacional, vol. 34, no. 2, pp. 347369, 2014.

[37] M. Kadziński, K. Ciomek, and R. Słowiński, "Modeling assignment-based pairwise comparisons within integrated framework for value-driven multiple criteria sorting," European Journal of Operational Research, vol. 241, no. 3, pp. 830-841, 2015.

[38] E. Jacquet-Lagrèze, "An application of the UTA discriminant model for the evaluation of R\&D projects," in Advances in Multicriteria Analysis, P. M. Pardalos, Y. Siskos, and C. Zopounidis, Eds., pp. 203-211, Kluwer Academic Publishers, Dordrecht, The Netherlands, 1995.

[39] C. Zopounidis and M. Doumpos, "A multicriteria decision aid methodology for sorting decision problems: the case of financial distress," Computational Economics, vol. 14, no. 3, pp. 197-218, 1999.

[40] S. Greco, B. Matarazzo, and R. Slowinski, "Rough sets theory for multicriteria decision analysis," European Journal of Operational Research, vol. 129, no. 1, pp. 1-47, 2001.

[41] S. Greco, V. Mousseau, and R. Słowiński, "Multiple criteria sorting with a set of additive value functions," European Journal of Operational Research, vol. 207, no. 3, pp. 1455-1470, 2010.

[42] C. Zopounidis and M. Doumpos, "Multicriteria classification and sorting methods: a literature review," European Journal of Operational Research, vol. 138, no. 2, pp. 229-246, 2002.

[43] D. C. Morais, A. T. de Almeida, and J. R. Figueira, "A sorting model for group decision making: a case study of water losses in Brazil," Group Decision and Negotiation, vol. 23, no. 5, pp. 937960, 2014.

[44] Y. Chen, D. Marc Kilgour, and K. W. Hipel, "Multiple criteria classification with an application in water resources planning," Computers and Operations Research, vol. 33, no. 11, pp. 33013323, 2006.

[45] R. Vetschera, Y. Chen, K. W. Hipel, and D. M. Kilgour, "Robustness and information levels in case-based multiple criteria sorting," European Journal of Operational Research, vol. 202, no. 3, pp. 841-852, 2010.

[46] Y. Chen, K. W. Li, D. M. Kilgour, and K. W. Hipel, "A case-based distance model for multiple criteria $\mathrm{ABC}$ analysis," Computers \& Operations Research, vol. 35, no. 3, pp. 776-796, 2008.

[47] C. Zopounidis and M. Doumpos, "PREFDIS: a multicriteria decision support system for sorting decision problems," Computers \& Operations Research, vol. 27, no. 7-8, pp. 779-797, 2000.

[48] M. Doumpos and C. Zopounidis, "Developing sorting models using preference disaggregation analysis: an experimental investigation," European Journal of Operational Research, vol. 154, no. 3, pp. 585-598, 2004.

[49] M. Köksalan and S. B. Özpeynirci, "An interactive sorting method for additive utility functions," Computers \& Operations Research, vol. 36, no. 9, pp. 2565-2572, 2009.

[50] F. Cai, X. Liao, and K. Wang, "A progressive multiple criteria sorting approach based on additive utility functions considering imprecise information," International Journal of Innovative Computing, Information and Control, vol. 7, no. 5, pp. 2727-2738, 2011.

[51] S. Greco, M. Kadziński, V. Mousseau, and R. Słowiński, "Robust ordinal regression for multiple criteria group decision: UTAGSM-GROUP and UTADISGSM-Group," Decision Support Systems, vol. 52, no. 3, pp. 549-561, 2012.

[52] S. Greco, M. Kadziski, and R. SŁowiński, "Selection of a representative value function in robust multiple criteria sorting," Computers \& Operations Research, vol. 38, no. 11, pp. 1620-1637, 2011.

[53] M. Kadziński, S. Greco, and R. Słowiński, "Selection of a representative value function for robust ordinal regression in group decision making," Group Decision \& Negotiation, vol. 22, no. 3, pp. 429-462, 2013.

[54] M. Kadziński and T. Tervonen, "Stochastic ordinal regression for multiple criteria sorting problems," Decision Support Systems, vol. 55, no. 1, pp. 55-66, 2013.

[55] A. T. de Almeida, C. A. V. Cavalcante, M. H. Alencar, R. J. P. Ferreira, A. T. de Almeida-Filho, and T. V. Garcez, Multicriteria and Multiobjective Models for Risk Reliability and Maintenance Decision Analysis, vol. 231 of International Series in Operations Research \& Management Science, Springer, New York, NY, USA, 2015. 


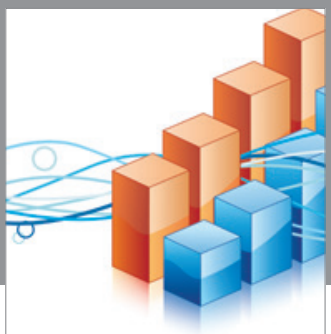

Advances in

Operations Research

vatem alat4

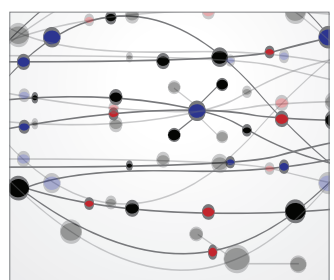

\section{The Scientific} World Journal
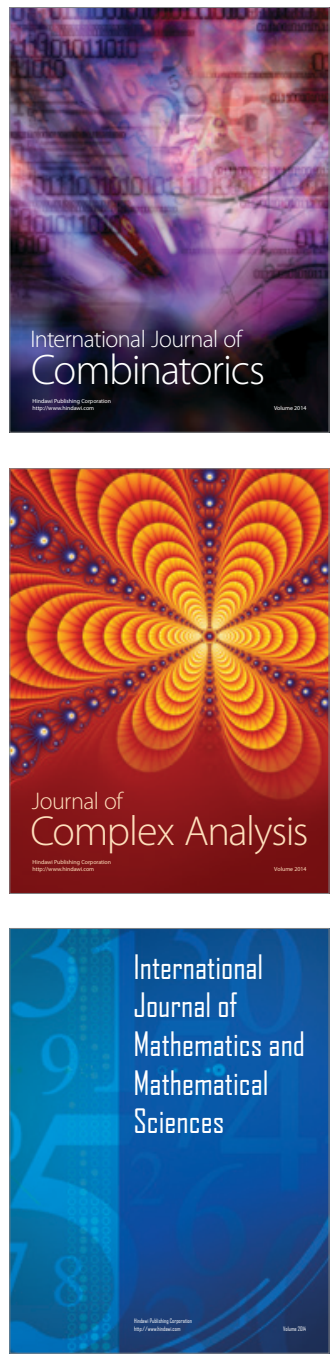
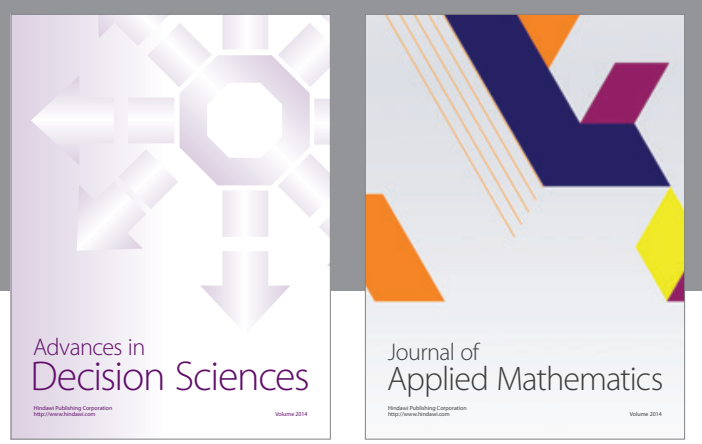

Algebra

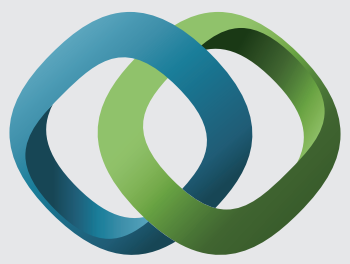

\section{Hindawi}

Submit your manuscripts at

http://www.hindawi.com
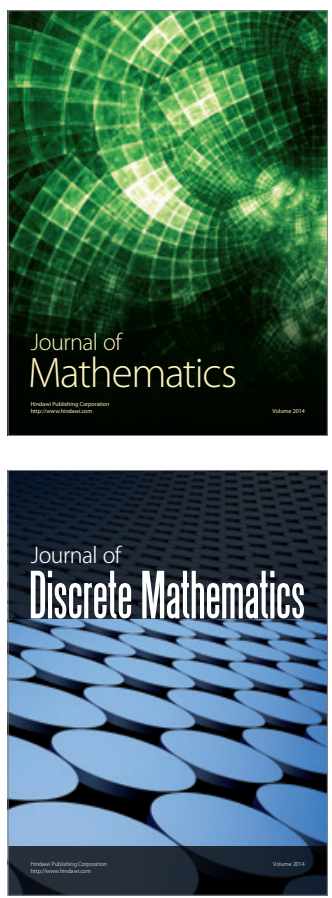

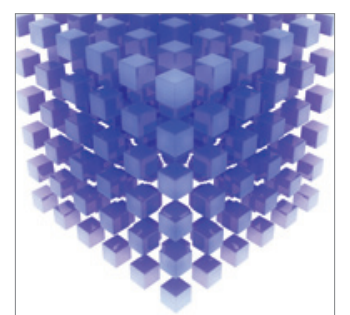

Mathematical Problems in Engineering
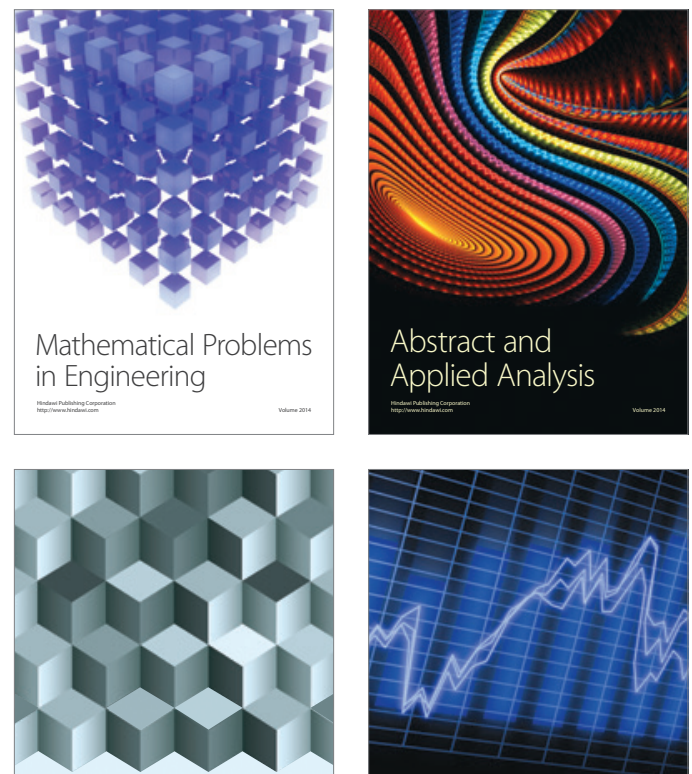

Journal of

Function Spaces

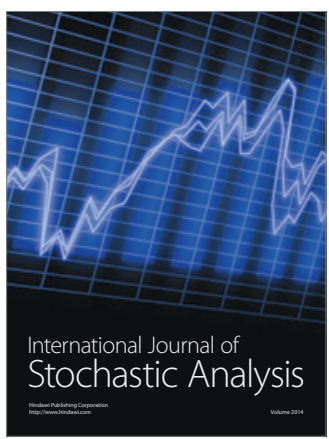

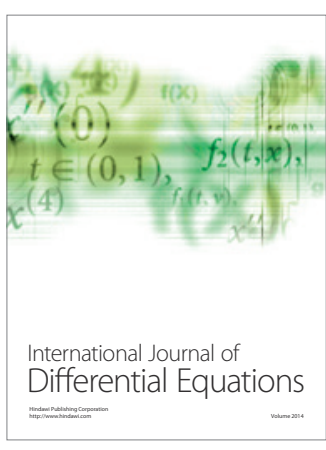
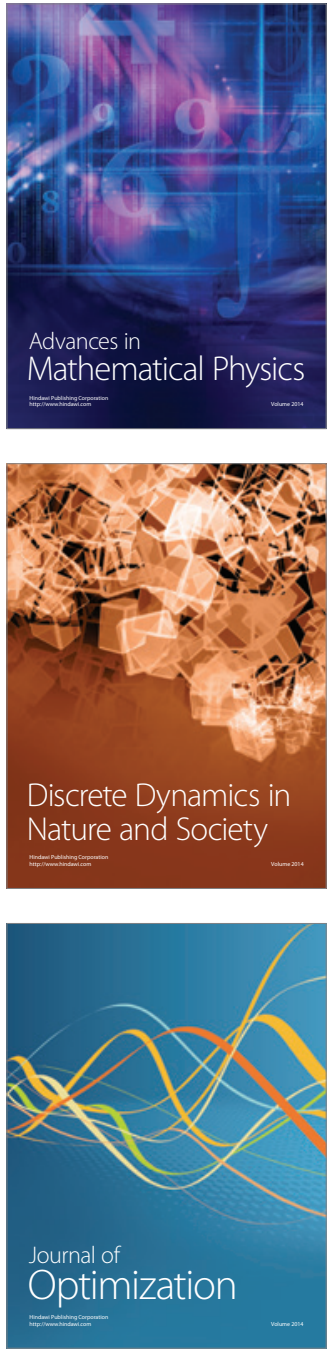